\title{
Usage of Sorbent-Catalyst to Accelerate the Oxidation of Manganese
}

\author{
Mykola Gomelya ${ }^{1}$, Mariia Tverdokhlib ${ }^{1}$, Tetyana Shabliy ${ }^{1 *}$, Olga Linyucheva ${ }^{1}$ \\ 1 Department of Ecology and Technology of Plant Polymers, Faculty of Chemical Engineering, Igor Sikorsky \\ Kyiv Polytechnic Institute, Peremogy Avenu 37/4, 03056 Kyiv, Ukraine \\ * Corresponding author's email: dsts1@ukr.net
}

\begin{abstract}
The processes of manganese (II) ions removal from water using sorbent catalysts and ion exchange materials modified with iron oxides were studied. It was shown that manganese ions oxidize very slowly in artesian water, even when the $\mathrm{pH}$ is adjusted to 9.0. Intensive aeration of solutions due to stirring also does not promote the oxidation of manganese (II) ions. The degree of manganese extraction due to oxidation is reduced from $20-30 \%$ for solutions with a concentration of manganese ions of 1 and $5 \mathrm{mg} / \mathrm{dm}^{3}$ to $11-15 \%$ for solutions with a concentration of 15 and $30 \mathrm{mg} / \mathrm{dm}^{3}$. A significant increase in the oxidation efficiency of manganese ions was achieved by using magnetite as a sorbent catalyst. The efficiency of water demanganization increases along with the intensity of water aeration when mixing solutions. It was established that strongly acid cation exchangers provide efficient extraction of manganese ions from water. At the same time, a high exchange capacity of strong acid cation exchange resin KU-2-8 in acid and salt form was noted. It was shown that the capacity of manganese ions of this cation exchange resin in the $\mathrm{Ca}^{2+}$-form is slightly lower. When using the KU-2-8 in $\mathrm{Ca}^{2+}$-form of cation exchange resin to remove manganese ions from the solution already in the first samples, the leakage of manganese ions at the level of $10 \mathrm{mg} / \mathrm{dm}^{3} \mathrm{and}$ above was observed. This indicates that this form of ion exchanger is not suitable for deep purification of water from manganese (II) ions. In order to increase the efficiency of manganese ion extraction from water, increase the duration of the filter cycle, magnetite and magnetite-modified KU-2-8 cation exchange resin were used as a sorbent-catalyst. It was shown that the cation exchange resin modified with magnetite provides the removal of a significant part of manganese ions due to catalytic oxidation on magnetite. The conditions of effective manganese extraction under static and dynamic conditions are determined.
\end{abstract}

Keywords: manganese (II) ions, oxidation, catalyst, sorbent, modified cation exchange resin, water purification, magnetite.

\section{INTRODUCTION}

Intense anthropogenic pressure on natural water bodies, destruction of water ecological systems has led to the fact that today there are almost no surface water sources, which are characterized by high water quality. Therefore, more priority sources of water supply with the use of groundwater are used more and more often, which in most cases are characterized by high hygienic indicators and stable composition. However, the use of such waters is to some extent complicated by their contamination in some springs with compounds of iron, manganese, hydrogen sulfide and nitrates. There is a seasonal excess of iron and manganese concentrations in surface water.

The removal of iron and hydrogen sulfide can be easily achieved by aeration and filtration of water [Podgorni et al., 2014]; nitrates are easily excreted on anion exchange resins [Kassim et al., 2019]. Purification of water from manganese (II) ions is a much more complex problem, as the $\mathrm{Mn}^{2+}$ ions in an aerated medium are oxidized tens to hundreds of thousands of times slower than the $\mathrm{Fe}^{2+}$ ions. [Li-HuaCheng et al., 2020].

The ion exchange removal of manganese ions from natural waters is problematic, as the concentrations of hardness ions in such waters are 
an order of magnitude higher than the concentration of manganese, which, accordingly, leads to the predominant removal of hardness ions from water. [Gomelya et al., 2017]. This significantly complicates the water treatment process and increases its cost. The same can be said about baromembrane processes of water purification (reverse osmosis and electrodialysis), which provide almost complete desalination of water [Prodanovic et al., 2013], whereas there is a need to remove a few milligrams of manganese from a liter of water.

Therefore, more promising in this case are the processes based on the use of manganese oxidation catalysts and sorbents with catalytic properties.

Recently, the works describing the processes of extraction of manganese ions from water by using sorption methods have been published. [Biela et al., 2016, Flieger et al., 2020]. Sorbents with a supported catalyst film, preferably manganese oxide, are often used to increase the purification efficiency. [Ormanci et al., 2013, Massoudinejad et al., 2014]. A catalyst for the oxidation of manganese ions based on manganese ore was also developed [Patent 93087 Ukraine, 2014].

It should be noted that the oxidation of $\mathrm{Mn}^{2+}$ ions, even in the presence of catalysts, largely depends on a set of factors [Mamchenko et al., 2012], such as: $\mathrm{pH}$, redox potential of the medium, the concentration of manganese and oxygen ions. The author [Mamchenko et al., 2013] concluded that the autooxidation reaction between $\mathrm{Mn}$ (II) and $\mathrm{MnO}_{2}$ in solutions does not occur at pH below 9.0.

In general, the oxidation of manganese (II) ions on the surface of catalysts is accompanied by the formation of $\mathrm{MnO}_{2}$. Although in the complete absence of chlorides, the formation of $\mathrm{Mn}_{2} \mathrm{O}_{3}$ is possible [Cerrato et al., 2011].

Recently, more and more attention is paid to biological methods of water demanganization [Geszvain et al., 2012, Sinha et al., 2013]. However, biochemical oxidation of manganese is a more complex process than sorption and chemical catalytic oxidation; moreover, it is often much slower than these processes. At the same time, the enzymatic oxidation of manganese can take place in high yield.

Sorption-catalytic extraction of the $\mathrm{Mn}^{2+}$ ions from water can be more technological, able to stably provide the required efficiency of water purification.
The use of magnetite and its derivatives for the oxidation of manganese (II) ions can be especially promising. After all, this catalyst provides high results in the deironing of water [Gomelya et al., 2016].

The aim of the work was to create a sorbentcatalyst for water demanganization using magnetite and modified cation exchange resin, evaluation of the efficiency of the developed catalyst, determination of the main stages of the process of manganese extraction from water.

In order to achieve this goal, the following tasks were set:

- to evaluate the effectiveness of the use of magnetite in the removal of manganese (II) ions from water.

- to determine the contribution of catalytic oxidation and ion exchange in the processes of water purification from manganese using cation exchange resin modified with magnetite.

- to investigate the processes of manganese (II) ions extraction from dilute solutions in artesian water using magnetite-modified cation exchange resins.

\section{MATERIALS AND METHODS}

Magnetite and magnetite-modified KU-2-8 cation exchange resin were used as catalysts and sorbent catalysts.

Magnetite was obtained according to the method described in the work [Radovenchik et al., 2020].

The modified KU-2-8 cation exchange resin was obtained in two stages. In the first stage, the ion exchange resin was treated with a solution containing the iron (II) and iron (III) ions in the ratio $\mathrm{Fe}^{2+}: \mathrm{Fe}^{3+}=1: 2$. The first stage lasted until the saturation of the cation exchange resin with iron ions. In the second stage, the cation exchange resin was treated with a $10 \%$ alkali solution. The mixture was stirred until complete hydrolysis of iron ions with the formation of magnetite in the pores of the cation exchange resin.

The processes of the cation exchange resin KU-2-8 modification can be described by the following equations:

$$
\begin{aligned}
& 8\left(P-\mathrm{SO}_{3}^{-}\right) H^{+}+\mathrm{Fe}^{2+}+2 \mathrm{Fe}^{3+} \rightarrow \\
& \rightarrow\left(P-\mathrm{SO}_{3}^{-}\right){ }_{8} \mathrm{Fe}^{2+}, \mathrm{Fe}_{2}^{3+}+8 \mathrm{H}^{+}
\end{aligned}
$$




$$
\begin{gathered}
\left(\mathrm{P}-\mathrm{SO}_{3}^{-}\right)_{8} \mathrm{Fe}^{2+}, \mathrm{Fe}_{2}^{3+}+8 \mathrm{NaOH} \rightarrow \\
\rightarrow 8 \mathrm{P}-\mathrm{SO}_{3}^{-} \mathrm{Na}+\mathrm{Fe}_{3} \mathrm{O}_{4}
\end{gathered}
$$

where: $P$ - polymeric residue of cation exchange resin.

Solutions of manganese sulfate in artesian water were used as working media, which had the following characteristics: hardness $\mathrm{H}=$ $4.4-4.8 \mathrm{mg}-\mathrm{eq} / \mathrm{dm}^{3}$, alkalinity $\mathrm{A}=4.2-4.7 \mathrm{mg}$ $\mathrm{eq} / \mathrm{dm}^{3}, \mathrm{pH}$ 7.7-7.79, concentration of calcium ions $\left[\mathrm{Ca}^{2+}\right]=3.4-3.8 \mathrm{mg}$-eq $/ \mathrm{dm}^{3}$, concentration of chlorides $\left[\mathrm{Cl}^{-}\right]=80 \mathrm{mg} / \mathrm{dm}^{3}$, concentration of sulfates $\left[\mathrm{SO}_{4}^{2-}\right]=41 \mathrm{mg} / \mathrm{dm}^{3}$. The concentration of manganese ions ranged from 1 to $340 \mathrm{mg} / \mathrm{dm}^{3}$.

The doses of magnetite during water demanganization under static conditions were 500 and $1000 \mathrm{mg} / \mathrm{dm}^{3}$. The consumption of the magnetite-modified KU-2-8 cation exchange resin was $20 \mathrm{~cm}^{3} / \mathrm{dm}^{3}$. The concentration of manganese ions in the solution for static studies was $1-30 \mathrm{mg} / \mathrm{dm}^{3}$.

Purification of water from manganese ions under static conditions was performed by contacting the solutions with magnetite or modified cation exchange resin for 5 hours without stirring and with stirring. Water samples for analysis of manganese content were taken every hour.

Based on the obtained data, the extent of water purification (\%) was calculated by the formula:

$$
E=\frac{\left(C_{0}-C\right)}{C_{0}} \cdot 100
$$

where: $C_{0}$ and $C$ - initial and equilibrium concentration of manganese (II) ions in solution, $\mathrm{mg} / \mathrm{dm}^{3}$.

Solutions of manganese sulfate in distilled and artesian water at concentrations of $\mathrm{Mn}^{2+}$ from 5 to $340 \mathrm{mg} / \mathrm{dm}^{3}$ were filtered during studies on the extraction of manganese ions on the KU-2-8 cation exchange resin and magnetite-modified cation exchange resin through ion exchange resin (loading volume $10 \mathrm{~cm}^{3}$ ). The consumption of solutions was $10 \mathrm{~cm}^{3} / \mathrm{min}$. The sample volume was $250-1000 \mathrm{mg} / \mathrm{dm}^{3}$. The concentration of manganese and $\mathrm{pH}$ were determined in the selected samples, and the residual hardness was also determined using artesian water.
Total dynamic exchange capacity (TDEC) $\left(\mathrm{mg}-\mathrm{eq} / \mathrm{dm}^{3}\right)$ was calculated by the formula:

$$
T D E C=\frac{\left(C_{0}-C_{i}\right) \cdot V_{S V}}{V_{i}}
$$

where: $C_{0}$ - initial concentration of ions in solution, g-eq $/ \mathrm{dm}^{3}$;

$C_{i}-$ concentration of ions in the $i$-th sample after sorption, $\mathrm{g}$-eq $/ \mathrm{dm}^{3}$;

$V_{S V}-$ sample volume, $\mathrm{dm}^{3}$;

$V_{i}$ - volume of ion-exchanging material, $\mathrm{dm}^{3}$.

\section{RESULTS AND DISCUSSION}

At the initial stage, the processes of water purification from manganese ions during oxidation by free contact of aqueous solutions with air were investigated both without stirring the solutions and with constant stirring.

In general, studies have confirmed the published data that the manganese ions are practically not released from the water during normal aeration, even when the $\mathrm{pH}$ rises to 9 . At a $\mathrm{pH}$ in the range from 7.51 to 8.28 for five hours was not observed reducing the concentration of manganese when using the $\mathrm{Mn}^{2+}$ solutions with a concentration of $1.0 ; 5.0 ; 15.0 ; 30.0 \mathrm{mg} / \mathrm{dm}^{3}$. When the $\mathrm{pH}$ of the solutions was adjusted to 9.00 as a result of simple settling, both without stirring and with stirring, the concentrations of manganese (II) changed insignificantly (Table 1). The maximum degree of withdrawal did not exceed $30 \%$.

As can be seen from Table 1, the efficiency of manganese extraction increased when used as a catalyst for magnetite in concentrations of 500 and $1000 \mathrm{mg} / \mathrm{dm}^{3}$. The degree of manganese extraction increased along with the concentration of magnetite. However, without stirring, the cleaning efficiency was also low. This is due to the fact that in a stationary solution, the diffusion of oxygen and $\mathrm{Mn}^{2+}$ ions to the catalyst surface is quite slow. In the case of mixing solutions at a dose of magnetite of $500 \mathrm{mg} / \mathrm{dm}^{3}$, almost complete extraction of manganese at low concentrations $\left(1-5 \mathrm{mg} / \mathrm{dm}^{3}\right)$ and a significant reduction in manganese content at initial concentrations of 15 and $30 \mathrm{mg} / \mathrm{dm}^{3}$ were achieved.

Given the fact that magnetite is a fairly fine material, its use under dynamic conditions is 
Table 1 - The dependence artesian water purification efficiency from manganese (II) ions on their initial concentration, oxidation time and dose of magnetite at $\mathrm{pH} 9.00$

\begin{tabular}{|c|c|c|c|c|c|c|c|c|c|c|c|}
\hline \multirow{2}{*}[\mathrm{Mn}^{2+}]{$_{\text {initial }}$} & \multirow{2}{*}{$\begin{array}{c}\text { Dose of } \\
\text { magnetite }\end{array}$} & \multicolumn{5}{|c|}{ Equilibrium concentration $\mathrm{Mn}^{2+}, \mathrm{mg} / \mathrm{dm}^{3}$} & \multicolumn{5}{|c|}{ Extent of water purification, \% } \\
\hline & & \multicolumn{10}{|c|}{ Contact duration, hours } \\
\hline \multicolumn{2}{|c|}{$\mathrm{mg} / \mathrm{dm}^{3}$} & 1 & 2 & 3 & 4 & 5 & 1 & 2 & 3 & 4 & 5 \\
\hline 1.0 & \multirow{4}{*}{--} & 1.0 & 0.9 & 0.9 & 0.9 & 0.9 & 0.0 & 10.0 & 10.0 & 10.0 & 10.0 \\
\hline 5.0 & & 4.0 & 3.5 & 3.5 & 3.5 & 3.5 & 20.0 & 30.0 & 30.0 & 30.0 & 30.0 \\
\hline 15.0 & & 14.5 & 13.5 & 13.0 & 13.0 & 13.0 & 3.0 & 10.0 & 13.3 & 13.3 & 13.3 \\
\hline 30.0 & & 29.1 & 28.5 & 28.0 & 27.5 & 27.0 & 3.0 & 5.0 & 6.7 & 8.3 & 10.0 \\
\hline $1.0^{*}$ & \multirow{4}{*}{--} & 0.9 & 0.8 & 0.8 & 0.8 & 0.8 & 10.0 & 20.0 & 20.0 & 20.0 & 20.0 \\
\hline $5.0^{*}$ & & 3.9 & 3.6 & 3.5 & 3.5 & 3.5 & 22.0 & 28.0 & 30.0 & 30.0 & 30.0 \\
\hline $15.0^{*}$ & & 14.2 & 13.3 & 12.9 & 12.8 & 12.8 & 5.3 & 11.3 & 14.7 & 14.7 & 14.7 \\
\hline $30.0^{*}$ & & 29.0 & 28.3 & 27.8 & 27.0 & 26.7 & 3.3 & 5.7 & 7.3 & 10.0 & 11.0 \\
\hline 1.0 & \multirow{4}{*}{500} & 0.6 & 0.5 & 0.5 & 0.4 & 0.4 & 40.0 & 50.0 & 50.0 & 60.0 & 60.0 \\
\hline 5.0 & & 4.0 & 3.5 & 3.0 & 3.0 & 3.0 & 20.0 & 30.0 & 40.0 & 40.0 & 40.0 \\
\hline 15.0 & & 13.0 & 12.1 & 11.3 & 11.0 & 11.0 & 13.3 & 19.3 & 24.7 & 26.7 & 26.7 \\
\hline 30.0 & & 28.0 & 26.0 & 25.0 & 25.0 & 25.0 & 6.7 & 13.3 & 16.7 & 16.7 & 16.7 \\
\hline $1.0^{*}$ & \multirow{4}{*}{500} & 0.3 & 0.2 & 0.1 & 0.1 & 0.1 & 70.0 & 80.0 & 90.0 & 90.0 & 90.0 \\
\hline $5.0^{*}$ & & 1.3 & 0.6 & 0.5 & 0.5 & 0.5 & 74.0 & 88.0 & 90.0 & 90.0 & 90.0 \\
\hline $15.0^{*}$ & & 3.8 & 3.0 & 2.5 & 2.5 & 2.5 & 74.7 & 80.0 & 83.3 & 83.3 & 83.3 \\
\hline $30.0^{*}$ & & 11.0 & 10.0 & 9.5 & 9.2 & 9.0 & 63.3 & 66.7 & 68.3 & 69.3 & 70.0 \\
\hline 1.0 & \multirow{4}{*}{1000} & 0.4 & 0.3 & 0.2 & 0.2 & 0.2 & 60.0 & 70.0 & 80.0 & 80.0 & 80.0 \\
\hline 5.0 & & 3.5 & 3.0 & 2.8 & 2.5 & 2.5 & 30.0 & 40.0 & 44.0 & 50.0 & 51.0 \\
\hline 15.0 & & 11.0 & 10.0 & 9.0 & 8.0 & 8.0 & 26.7 & 33.3 & 40.0 & 46.7 & 46.7 \\
\hline 30.0 & & 24.0 & 23.0 & 22.8 & 22.5 & 22.4 & 20.0 & 23.3 & 24.0 & 25.0 & 25.3 \\
\hline
\end{tabular}

- While stirring the solution.

significantly complicated by significant hydraulic resistance, which, accordingly, significantly reduces the rate of filtration of solutions through magnetite. Therefore, we obtained the samples of KU-2-8 cation exchange resin, modified with magnetite, as described above.

This material has previously been used successfully to accelerate the oxidation of iron during water aeration [Radovenchik et al., 2020]. It has provided effective extraction of iron at simple contact of its solutions with air.

The modified cation exchange resin was used in the purification of manganese sulfate solutions in artesian water under static conditions (Table 2). The reaction medium $(\mathrm{pH})$ in these solutions was in the range of 7.2-7.7. As can be seen from Table 2, under static conditions using cation exchange resin modified with magnetite, almost complete removal of manganese ions from water was achieved. Given that the technology of water purification using oxidation under static conditions is quite complex, we used unmodified and modified KU-2-8 cation exchange resin under dynamic conditions.

It should be noted that when modifying the KU-2-8 cation exchange resin with magnetite at the last stage of the process, the resin is treated with alkali. In this case, the $\mathrm{Fe}^{2+}$ and $\mathrm{Fe}^{3+}$ ions in the pores of the ion exchange material form magnetite $\mathrm{Fe}_{3} \mathrm{O}_{4}$, and the cation exchange resin itself turns into $\mathrm{Na}^{+}$-form and can effectively sorb cations from solutions, including the $\mathrm{Mn}^{2+}$ cations. We studied the processes of sorption of manganese ions on the KU-2-8 cation exchange resin depending on its form (Fig. 1).

As can be seen from Figure 1, the cation exchange resin effectively absorbs manganese in $\mathrm{H}^{+}$- and $\mathrm{Na}^{+}$-forms. In the $\mathrm{Ca}^{2+}$-form, the capacity of the cation exchange resin reaches $1700 \mathrm{mg}$-eq/ $\mathrm{dm}^{3}$, while in the $\mathrm{H}^{+}$- and $\mathrm{Na}^{+}$-forms the capacity of the cation exchange resin in manganese exceeds $2000 \mathrm{mg}$-eq $/ \mathrm{dm}^{3}$. In this case, when using cation exchange resin in the $\mathrm{Ca}^{2+}$-form, a leakage of manganese ions in the concentrations greater than $10 \mathrm{mg} / \mathrm{dm}^{3}$ is observed in the first samples of the filtered solution. This indicates that at low concentrations of manganese ions, they will be practically not sorbed on the cation exchange resin in the $\mathrm{Ca}^{2+}$-form, due to the high selectivity of the cation exchange resin for calcium ions.

It is known that when sorption of heavy metals from water occurs in the presence of hardness 
Table 2 - The dependence of manganese ions residual concentration, the degree of extraction of manganese ions from artesian water and the $\mathrm{pH}$ of the medium from the time of mixing of solutions using magnetite-modified KU-2-8 cation exchange resin in the amount of $20 \mathrm{~cm}^{3} / \mathrm{dm}^{3}$

\begin{tabular}{|c|c|c|c|c|c|c|c|c|c|c|c|c|}
\hline \multirow{3}{*}[\mathrm{Mn}^{2+}]{$_{\text {initial }}$} & \multicolumn{5}{|c|}{ Equilibrium concentration $\mathrm{Mn}^{2+}, \mathrm{mg} / \mathrm{dm}^{3}$} & \multicolumn{5}{|c|}{ Extent of water purification, $\%$} & \multirow{3}{*}{$\mathrm{pH}_{\text {initial }}$} & \multirow{3}{*}{$\mathrm{pH}_{\text {fina }}$} \\
\hline & \multicolumn{5}{|c|}{ Stirring duration, hours } & \multicolumn{5}{|c|}{ Stirring duration, hours } & & \\
\hline & 1 & 2 & 3 & 4 & 5 & 1 & 2 & 3 & 4 & 5 & & \\
\hline 1.0 & 0.50 & 0.30 & 0.25 & 0.25 & 0.10 & 50 & 70 & 75 & 75 & 90 & 8.998 & 7.736 \\
\hline 5.0 & 0.85 & 0.50 & 0.25 & 0.25 & 0.10 & 83 & 90 & 95 & 95 & 98 & 8.989 & 7.743 \\
\hline 15.0 & 5.00 & 1.30 & 0.80 & 0.40 & 0.15 & 67 & 91 & 95 & 97 & 99 & 8.947 & 7.711 \\
\hline 30.0 & 10.00 & 3.50 & 1.50 & 0.60 & 0.20 & 67 & 88 & 95 & 98 & 99 & 8.878 & 7.696 \\
\hline
\end{tabular}

ions, the capacity of the cation exchange resin on heavy metal is as many times smaller than the capacity of hardness ions, as many times lower its equivalent concentration in solution is [Trokhymenko et al., 2017]. That is, at a manganese concentration of $1-5 \mathrm{mg} / \mathrm{dm}^{3}$, or $0.036-0.182 \mathrm{mg}$-eq/ $\mathrm{dm}^{3}$, and at a water hardness of approximately $4.3 \mathrm{mg}-\mathrm{eq} / \mathrm{dm}^{3}$, the manganese ion capacity will be at least 20 times lower than the hardness ion capacity and will not exceed $100 \mathrm{mg}$ $\mathrm{eq} / \mathrm{dm}^{3}$. This means that in this case, when using cation exchange resin, the main process will not be the removal of manganese ions, but the softening of water.

In some cases, especially when preparing drinking water, such deep softening is impractical. In addition, the process is significantly complicated by the need to periodically regenerate the cation exchange resin from hardness ions. At the same time, there is a difficult problem of utilizing the fulfilled regeneration solutions.

Therefore, we used magnetite-modified cation exchange resin to extract manganese from water in both the $\mathrm{Na}^{+}$- and $\mathrm{Ca}^{2+}$-form (Fig. 2).
In the case of using magnetite-modified KU-2-8 cation exchange resin, efficient extraction of manganese ions is ensured both at the stage when the ion exchange resin is in the $\mathrm{Na}^{+}-$ form and effectively sorbs double-charged cations from water and at the stage when the cation exchange resin is completely saturated with hardness ions and manganese ions.

As can be seen from Figure 2, the manganese ions were completely removed on the modified cation exchange resin in the $\mathrm{Na}^{+}$-form at their concentration in solution at the level of $5 \mathrm{mg} / \mathrm{dm}^{3}$ (Fig. 2, curve 1). If 7-8 $\mathrm{dm}^{3}$ of water was missing in the first stage, manganese extraction was possible both due to sorption on the cation exchange resin and catalytic oxidation on the magnetite, then later, when all the cation exchange resin turned into the $\mathrm{Ca}^{2+}$, $\mathrm{Mg}^{2+}$-form, manganese extraction was mainly due to catalytic oxidation on magnetite. This is also confirmed by the data shown in Fig. 2 (curve 2, 4).

In this case, the cation exchange resin was previously converted to the $\mathrm{Ca}^{2+}$-form. Therefore,

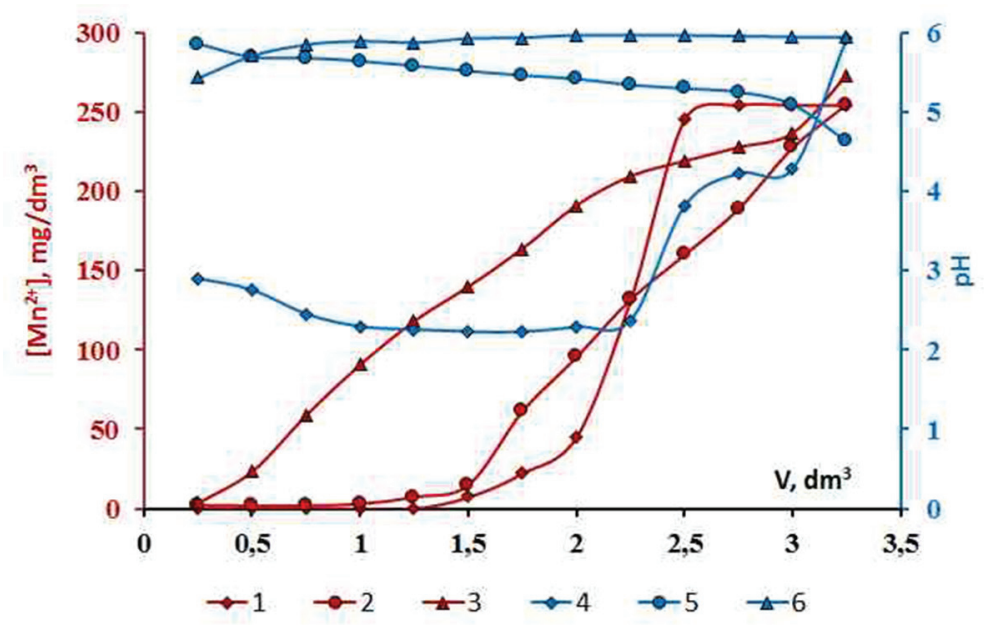

Fig. 1. Dependence of residual concentration of manganese ions $(1 ; 2 ; 3)$ and $\mathrm{pH}(4 ; 5 ; 6)$ on the volume of the passed solution and the form of the KU-2-8 cation exchange resin $\left(\mathrm{V}_{\mathrm{i}}=10 \mathrm{~cm}^{3}\right)$ : $\mathrm{H}^{+}$-form $(1 ; 4), \mathrm{Na}^{+}$-form

$(2 ; 5), \mathrm{Ca}^{2+}$-form $(3 ; 6)\left(\mathrm{TDEC}_{1}=2187 \mathrm{mg}-\mathrm{eq} / \mathrm{dm}^{3} ; \mathrm{TDEC}_{2}=2169 \mathrm{mg}-\mathrm{eq} / \mathrm{dm}^{3} ; \mathrm{TDEC}_{3}=1708 \mathrm{mg}\right.$-eq $\left./ \mathrm{dm}^{3}\right)$ 


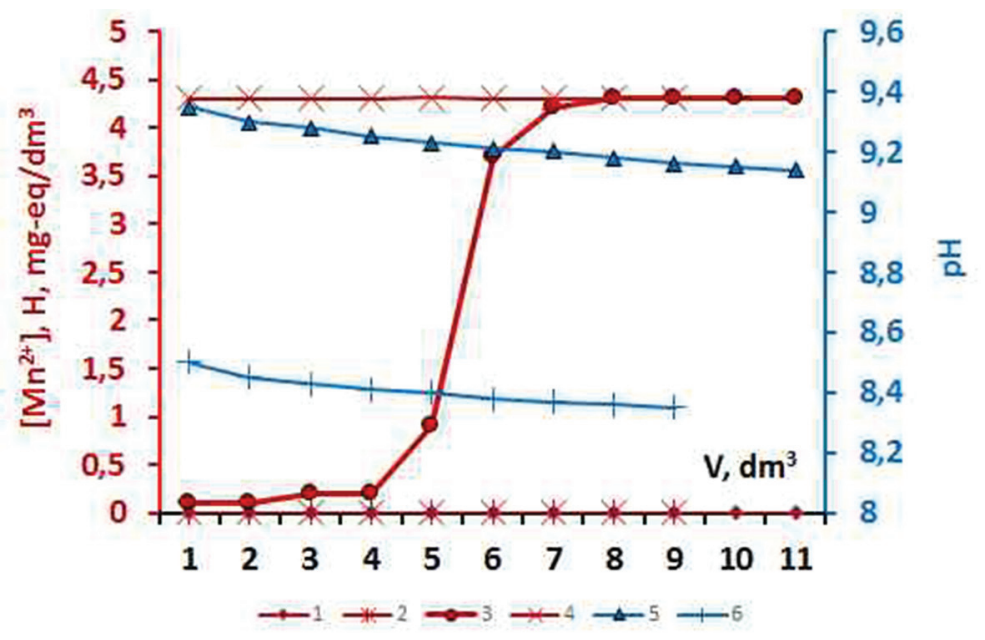

Fig. 2. Change in the concentration of manganese ions $(1,2)$, hardness $(3,4)$ and $\mathrm{pH}(5,6)$ depending on the missed volume of a solution of manganese sulfate $\left(\left[\mathrm{Mn}^{2+}\right]=5 \mathrm{mg} / \mathrm{dm}^{3}\right)$ in artesian water through the KU-2-8cation exchange resin, modified with magnetite $\left(\mathrm{V}_{\mathrm{i}}=10 \mathrm{~cm}^{3}\right)$ and cation exchange resin forms: $\mathrm{Na}^{+}$- form $(1,3,5) ; \mathrm{Ca}^{2+}$-form $(2,4,6)$

it did not absorb the hardness ions from the water. Its capacity was also small during the sorption of manganese ions at their concentration of $5 \mathrm{mg} / \mathrm{dm}^{3}$. It is obvious that the bulk of manganese ions were removed from the water due to catalytic oxidation on magnetite.

Obviously, in the first, rather limited stage of water purification, the processes of sorption of manganese ions along with hardness ions mainly prevail. Subsequently, when the exchange capacity of the cation exchange resin is exhausted, the extraction of manganese occurs mainly due to its oxidation on magnetite. It is likely that manganese oxide $\left(\mathrm{MnO}_{2}\right)$ is included in the structure of magnetite or fixed in the porous polymer material that is the basis of the cation exchange resin. All this ensures the maintenance of catalyst activity. Therefore, it can work for a long period of time. It is advisable to use mechanical filters to trap the $\mathrm{MnO}_{2}$ particles that can be washed out of the sorbent.

The possibility of oxidation of manganese ions on the magnetite deposited on the KU-2-8 cation exchange resin in the $\mathrm{Na}^{+}$-form can be judged from the data shown in Figure 3.

As can be seen from Figure 3, the total exchange capacity of the unmodified KU-2-8 cation exchange resin for $\mathrm{Mn}^{2+}$ ions reached $2169 \mathrm{mg}$-eq $/ \mathrm{dm}^{3}$, and the magnetite-modified cation exchange resin reached $2861 \mathrm{mg}-\mathrm{eq} / \mathrm{dm}^{3}$. This suggests that even at relatively high concentrations of manganese ions in solutions, some ions are removed by sorption and some by oxidation on magnetite.
These assumptions are confirmed by the fact that when filtering a solution of manganese sulfate through the magnetite-modified cation exchange resin in the $\mathrm{Na}^{+}$-form, its capacity for manganese ions was $32 \%$ higher compared to the unmodified cation exchange resin (Fig. 3). It is obvious that even under these conditions, $32 \%$ of the manganese ions present in the solution were oxidized on magnetite by dissolved oxygen. However, this is at a manganese concentration of $340 \mathrm{mg} / \mathrm{dm}^{3}$ and an oxygen concentration of $8 \mathrm{mg} / \mathrm{dm}^{3}$.

At lower concentrations of manganese, the contribution of oxidation in the process of purification of water from manganese ions is significantly higher. At least in the process of water demanganization on the modified cation exchange resin in the $\mathrm{Ca}^{2+}$-form (Fig. 2), it is quite probable that the oxidation processes of manganese predominate over the processes of its sorption.

\section{CONCLUSIONS}

It was shown that magnetite at a concentration of $500 \mathrm{mg} / \mathrm{dm}^{3}$ and the magnetite-modified KU-2-8 cation exchange resin in the amount of $20 \mathrm{~cm}^{3} / \mathrm{dm}^{3}$ provide effective removal of manganese ions from solutions with a concentration of $1-30 \mathrm{mg} / \mathrm{dm}^{3}$ with stirring in contact with air.

It was established that when using the magnetite-modified KU-2-8 cation exchange resin in the extraction of manganese ions from water, it is possible to extract the manganese ions both due to ion exchange and due to their catalytic 


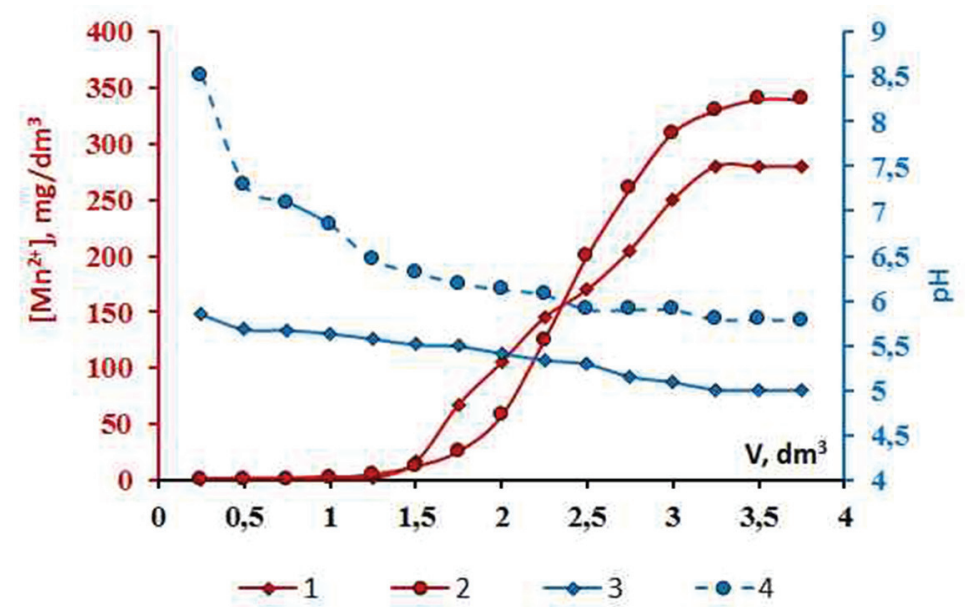

Fig. 3. Change in the concentration of manganese ions $(1 ; 2)$ and $\mathrm{pH}(3 ; 4)$ depending on the passed through volume of manganese sulfate solution $\left[\left[\mathrm{Mn}^{2+}\right]=280 \mathrm{mg} / \mathrm{dm}^{3}, \mathrm{pH} 5.93 ;\left[\mathrm{Mn}^{2+}\right]=340 \mathrm{mg} / \mathrm{dm}^{3}\right.$, $\mathrm{pH}$ 8.97) through unmodified $(1 ; 3)$ and modified with the CU-2-8 magnetite $(2 ; 4)$ cation exchange $\operatorname{resin}\left(\mathrm{V}_{\mathrm{i}}=10 \mathrm{~cm}^{3}\right)$ in the $\mathrm{Na}^{+}$- form $\left(\mathrm{TDEC}_{1}=2169 \mathrm{mg}-\mathrm{eq} / \mathrm{dm}^{3} ; \mathrm{TDEC}_{2}=2861 \mathrm{mg}-\mathrm{eq} / \mathrm{dm}^{3}\right)$

oxidation on magnetite with dissolved oxygen. It was shown that when using the magnetite-modified cation exchange resin during sorption of the manganese ions from a solution with a concentration of $340 \mathrm{mg} / \mathrm{dm}^{3}$, its capacity for manganese is $32 \%$ higher in comparison with the unmodified cation exchange resin. This is due to the catalytic oxidation of manganese on magnetite.

It was shown that at a concentration of manganese in artesian water at the level of $5 \mathrm{mg} / \mathrm{dm}^{3}$ when purifying the solution under dynamic conditions on the KU-2-8 cation exchange resin modified with magnetite, at a volume of $10 \mathrm{~cm}^{3}$ ionite, complete extraction of manganese is provided by filtering more than $10 \mathrm{dm}^{3}$ water.

\section{Acknowledgments}

The work was supported by National research fund of Ukraine, grant No. 144/01.2020.

\section{REFERENCES}

1. Biela, R., Kucera, T. 2016. Efficacy of sorption materials for nickel, iron and manganese removal from water. Procedia Engineering, 162, 56-63.

2. Cerrato, J.M., Knocke, W.R., Hochella, M.F., Andrea, Jr., Dietrich, M., Jones, A., Cromer, T.F. 2011. Application of XPS and solution chemistry analyses to investigate soluble manganese removal by MnOx(s)-Coated Media. Environmental Scientific Technology, 45(23), 10068-10074.

3. Flieger, J., Kawka, J., Plazinski, W., Panek, R., Madej, J. 2020. Sorption of heavy metal ions of chromium, manganese, selenium, nickel, cobalt, iron from aqueous acidic solutions in batch and dynamic conditions on natural and synthetic aluminosilicate sorbents. Materials, 13, 5271.

4. Geszvain, K., Butterfield, C., Davis, R.E., Madison, A. 2012. The molecular biogeochemistry of manganese (II) oxidation. Biochemical Society Transactions, 40(6), 1244-1248.

5. Gomelya, M., Tverdokhlib, M. 2016. Research of efficiency of water purification-exchange resin from iron compounds using modified filter media. Eastern-European Journal of Enterprise Technologies, 2(10(80)), 47-52.

6. Gomelya, N., Ivanova, V., Galimova, V., Nosachova, J., Shabliy, T. 2017. Evaluation of cationite efficiency during extraction of heavy metal ions from diluted solutions. Eastern-European Journal of Enterprise Technologies, 5/6(89), 4-10.

7. Kassim, A.A., Abdullah, N., Yahya, M.Z. 2019. The pre-evaluation of crosslinked anion exchange (CAX) resin on nitrates removal. Journal of Chemical Engineering and Industrial Biotechnology, 5(2), 1-8.

8. Li-Hua Cheng, Zhao-Zhao Xiong, Shuo Cai, DuWang Li, Xin-Hua Xu 2020. Aeration-manganese sand filter-ultrafiltration to remove iron and manganese from water: Oxidation effect and fouling behavior of manganese sand coated film. Journal of Water Process Engineering, 38, 101621.

9. Mamchenko, A.V., Chernova, N.N. 2012. Determination of basic parameters affecting the water treatment from manganese compounds on the sorbent-catalyst. Journal of Water Chemistry and Technology, 34, 234-239.

10. Mamchenko, A.V., Chernova, N.N. 2013. Water purification of manganes compounds by a sorbent-catalyst 
at diferent $\mathrm{pH}$ and salt content. Journal of Water Chemistry and Technology, 34, 30-35.

11. Massoudinejad, M., Khashij, M. 2014. Absorption isotherm study of $\mathrm{Mn}^{2+}$ on $\mathrm{MnO}_{2}$ and $\mathrm{FeO}$ - coated zeolite from aqueous solution. International Journal of Advanced Science and Technology, 72, 63-72.

12. Ormanci, T., Demirkol, G.T., Aydın, I.M., Tufekci, N. 2013. An experimental study on manganese(II) removal with manganese dioxide recycling. Desalination and Water Treatment, 51(10-12), 2225-2230.

13. Patent 93087 Ukraine: MPK B01J 20/02, CO2F 1/64 The method of obtaining a load for water purification from manganese compounds: Publ. 25.09.2014, Bulletin No. 14.

14. Podgorni, E., Rzasa, M. 2014. Investigation of the effects of salinity and temperature on the removal of iron from water by aeration, filtration and coagulation. Polish Journal of Environmental Studies,
23(6), 2157-2161.

15. Prodanovic, J.M., Vasic, V.M. 2013. Application of membrane processes for distillery wastewater purification (a review). Desalination and Water Treatment, 51(16-18), 3325-3334.

16. Radovenchik V.M., Ivanenko O.I., Radovenchik Y.V. and Krisenko T.V. 2020. Application of Ferrite Materials in Water Purification Processes, Monograph. Bila Tserkva: O.V. Pshonkivsky, 215. (In Ukrainian).

17. Sinha, A., Khare, S.K. 2013. Manganese: its speciation, pollution and microbial mitigation. International Journal of Applied Sciences and Biotechnology, 1(4), 162-170.

18. Trokhymenko, G., Gomelya, M. 2017. Development of low waste technology of water purification from copper ions. Chemistry and Chemical Technology, 11(3), 372-377. 